\title{
A Michael Handelsman: pensador-hacedor-escritor de afán intercultural y decolonial
}

To Michael Handelsman: thinker-maker-writer

of intercultural and de-colonial zeal

\section{Catherine Walsh}

Universidad Andina Simón Bolívar, Sede Ecuador, Quito

DOI: https://doi.org/10.32719/13900102.2019.45.1

Fecha de recepción: 28 enero 2019

Fecha de aceptación: 15 abril 2019 


\section{RESUMEN}

Esta carta dirigida a Michael Handelsman es un ejercicio de reflexión en el que Catherine Walsh escribe "con-versando y co-pensando" con el explícito propósito de recordar y destacar la labor literaria, intercultural y decolonial de Handelsman, en relación a su labor como estudioso de la literatura ecuatoriana, de manera particular afro-ecuatoriana, cuya mirada afrocentrada no ha dejado de leer, desde ese lugar, la cultura y la sociedad en su conjunto. Las palabras de Walsh se entretejen desde una rotunda crítica al poder letrado y una declarada empatía afectiva "personal-político-intelectual" con su interlocutor, como lugares privilegiados de enunciación.

PALABRAS CLAVE: Michael Handelsman, Ecuador, afrocentrismo, literatura afroecuatoriana, interculturalidad, literatura, plurinacionalidad, "casa adentro".

\section{ABSTRACT}

This letter to Michael Handelsman is an exercise of reflection in which Catherine Walsh writes " $c o(n)$ versifying and co-thinking" with said author. The clear purpose is to remember and highlight the literary, intercultural and de-colonial task carried out by Handelsman, with relation to his work as a scholar devoted to Ecuadorian Literature, particularly, Afro-Ecuadorian, without having left aside -despite adopting the aforementioned point of view-, a reading of culture and society as a whole. Walsh's words arise from a strong critic against literate power and a declared "personal-political-intellectual" empathy with her interlocutor, as privileged places of expression.

KEYwords: Michael Handelsman, Ecuador, afrocentrism, Afro-Ecuadorian Literature, interculturality, Literature, plurinationality, "inside the house".

No me ATrevo a escribir sobre ti, Michael. No solo que no me atrevo, no puedo. Convertirte en un “objeto" de estudio, en el objeto de mi reflexión, contribuiría, sin duda, al individualismo propio del mundo letrado que tú mismo has criticado. Además, disimularía y neutralizaría nuestra larga amistad y nuestra relación personal-político-intelectual de co-labor. Por tanto, y de manera nada usual, escribo con-versando y co-pensando. En una suerte de carta pública, me dirijo a ti y a tu labor literaria, intercultural y decolonial construida desde y con esta tierra ecuatoriana.

Empiezo no con lo que puedo decir sobre ti, sino con lo que tú narras sobre ti mismo. En la introducción a tu libro Género, raza y nación, cuentas algo sobre tus propios caminos con y desde la literatura, incluyendo las tensiones entre "los localismos que supuestamente nos privan de una deseada universalidad". La reflexión inicia con Faulkner y sus novelas Mientras agonizo y El sonido y la furia. 
Yo me crié en New Jersey -el Norte- y el Mississippi [de Faulkner] de los años 20 y 30 del siglo pasado me resultaba muy lejos, muy anticuado y muy 'pequeño' ...demasiado local y distante. Así pensaba cuando tenía apenas 15 años, y seguramente mi falta de experiencia y madurez intelectual me ofuscaba el panorama literario. Pero, curiosamente, no fue hasta años después, cuando había descubierto en castellano a Juan Rulfo y su Pedro páramo y El Ilano en llamas que pude comprender lo arbitrario y perjudicial de los esquemas imperiales y coloniales: es decir, yo, de EEUU, tuve que viajar primero a Comala y conocerla en castellano antes de poder apreciar a Faulkner en inglés. ...Primero Comala y, luego, Ecuador me han sacado de mi encierro cultural para, así, conocer realmente el mundo $(2008,6)$.

Esta experiencia vivida, como bien explicas, pone en escena el problema mismo de la colonialidad, su construcción de 'lo pequeño' (versus 'lo grande' de la modernidad occidental), sus jerarquías valorativas y normativas propias "que nos condena a vivir en un mundo excluyente y discriminatorio, un mundo que todavía no ha logrado comprender desde una complementariedad capaz de fomentar y alimentar la convivencia de las diferencias" (Handelsman 2008, 6-7). Así, y para ti, tiene mucho sentido la reflexión de Antonio Cornejo Polar sobre la relación entre literatura y la "totalidad social", sobre el constante diálogo -consciente o no- de la literatura con otros procesos culturales y sociales dentro y fuera de la llamada ciudad letrada.

De hecho, tu labor a lo largo de las últimas décadas ha estado dedicada a visibilizar este diálogo, a no solo confundir y complementar lo pequeño y lo grande, sino también, y tal vez más importante aún, hacer presente subjetividades, identidades y voces que rompen las historias y los imaginarios hegemónicos, que interculturalicen y plurinacionalicen la "totalidad social". Recuerdo, como ejemplo, tu libro Lo afro y la plurinacionalidad: el caso ecuatoriano visto desde su literatura (2001). Con este texto abriste la conceptualización y construcción del discurso de lo plurinacional desde la heterogeneidad del país y desde los márgenes de la llamada 'nación', argumentando con fuerza y claridad a favor del necesario reconocimiento de la presencia afrodiaspórica, afroandina y afroecuatoriana en un país y región "definido en términos tripartitas: los blancos, los mestizos y los indios" (12). Al momento de resaltar el conflicto y la tensión racializados, y pensar desde ahí, no temiste tomar una posición incluso ante el poder letrado.

A diferencia de la llamada "literatura negrista" de los años cincuenta, tu proyecto no fue hablar por los pueblos (o literatos) afroecuatorianos. Fue, más bien, suscitar una comprensión intercultural (aunque no usabas 
el término en este momento) de la plurinacionalidad y caminar la plurinacionalización desde la literatura. Proponías una nueva óptica, anclada en el afrocentrismo, para leer la literatura y también para leer la sociedad. "En efecto, el afrocentrismo como método crítico, tanto en los estudios literarios como en cualquier otro campo, revela que el interés en resaltar lo afro trasciende separatismos ya que complementa las vivencias que siguen formando el conjunto plurinacional del Ecuador" (2001, 12).

Si recuerdas, tuvimos nuestras discusiones y diferencias sobre el término afrocentrismo. Yo argumentaba la distinción entre los contextos de Estados Unidos, donde el término-concepto fue acuñado por académicos negros, y de Ecuador en donde la frase "casa adentro" marca el hablar-hacer-pensar de las comunidades. No obstante, y algunos años después, aclaraste tu posición frente a mi crítica:

Somos de la opinión que mientras que el público ecuatoriano en su mayoría se ha mostrado poco interesado en lo afroecuatoriano más allá de la Selección Nacional de Fútbol y de ciertas curiosidades culturales, el concepto y práctica de 'casa adentro' que Juan García sigue impulsando desde las comunidades afros y sus respectivos territorios complementa y complejiza lo que entendemos por la intencionalidad transformativa planteada por el afrocentrismo ..., el mismo que pretende resignificar las relaciones sociales del poder hegemónico desde los saberes ancestrales subalternizados afros (Handelsman, "Nelson Estupiñán Bass en contexto", nota 5, 129-30).

Además, y como seguías argumentando:

Aunque no es nuestra intención confundir un concepto académico con un posicionamiento social y político arraigado en un entorno geográfico concreto, creemos que 'casa adentro' nos ayuda a contextualizar el afrocentrismo académico y emplearlo como una efectiva herramienta crítica y de aproximación más centrada en las experiencias vividas por los afrodescendientes del Ecuador (y de otros lares de la diáspora afro) y, así, evitar las inevitables trampas coloniales de las abstracciones teóricas (129-30).

De hecho eso ha sido parte de tu labor, Michael, a lo largo de muchos años: leer las experiencias vividas, contadas y expresadas por los afrodescendientes del Ecuador, y pensar con su perspectiva y uso particular -afrocentrista y de esencialismo estratégico dirías- de "casa adentro". "La insistencia en lo afro como una identidad particular, fundamentada en 
una herencia cultural e histórica" es, sin duda, "un acto de reapropiación y confrontación que invierte y subvierte todo un sistema de relaciones de poder propio de la colonialidad", decías $(2005,70)$. Pero también decías que es una estrategia intercultural. Argumentas que para ti lo propio no se entiende como "una finalidad absoluta de los procesos de autoafirmación afro". Más bien, es "un medio que, a largo plazo, conducirá a una interculturalidad que permita la plena participación de todos los sectores ecuatorianos desde sus respectivas diferencias" $(2005,92-3)$. Es esta interculturalidad, creo yo, la que marca y define tu proyecto, Michael. $\mathrm{Me}$ refiero a tu afán metodológico-pedagógico de interculturalizar la sociedad ecuatoriana y, por supuesto, a todas las personas que leen tus obras; un afán que a la vez transversa tu propia persona.

Mientras tu interés en la producción literaria afroecuatoriana -de Adalberto Ortiz, Argentina Chiriboga, Nelson Estupiñán Bass y Antonio Preciado- es de larga data, tus procesos de entablar diálogos con las posturas político-identitario-epistémicas de Juan Montaño y de Juan García Salazar son más recientes; si no estoy mal, empezaron más o menos por ahí en 2004-2005. Aunque ya conocías algo de la producción escrita de Montaño, tenías menos familiaridad con la de García. Recuerdo que me pediste sus textos. Casi enseguida empezaste a referirte $-\mathrm{y}$ en los años siguientes con más fuerza- a su postura con el propósito de fortalecer lo propio de "casa adentro" con respecto a la historia, la memoria, los saberes, el territorio ancestral y la etnoeducación. En un par de oportunidades, en la Universidad Andina Simón Bolívar, dentro del marco tanto del Fondo Documental Afro-Andino ${ }^{1}$ como del Doctorado de Estudios Culturales Latinoamericanos (donde sigues participando como profesor), tuviste la oportunidad de escucharle e intercambiar palabras con él. Fue en estos mismos años de la última década de los 2000, que empezábamos nuestro proyecto de colaboración entre la Universidad de Tennessee y la Universidad Andina, que incluía un enfoque en la diáspora africana y, entre otras actividades, el catálogo y exposición El color de la diáspora, con fotografías y textos de Juan García y fotografías de Edizon León (2006).

1. El Fondo Documental Afro-Andino, formado en 2002 como convenio entre la UASB y el colectivo Proceso de Comunidades Negras representado por Juan García Salazar, mantiene en comodato el archivo más grande de la región de material oral, visual y escrito de la memoria colectiva de las comunidades afroecuatorianas. 
Así, durante estos años, atestigüé un empeño tuyo no solo por transgredir, traspasar e interculturalizar el campo (y análisis) literario, sino también, y a la vez, tu propio lugar y postura de enunciación. Releer a Ortiz, Estupiñán Bass y Preciado, pensando con Montaño, García y también con el Abuelo Zenón (personaje ancestral que sigue impactando la memoria colectiva del pueblo afropacífico y afroecuatoriano), como has hecho en varios textos, es parte de la transgresión e interculturalización, parte de una postura político-epistémica y de una deliberada pensacción que invierte la atención hacia los conocimientos y la memoria colectiva sembrados en territorio, en y por las luchas de resistencia y re-existencia que permanecen hasta hoy. En todo eso, tu voz y pluma han contribuido, y siguen contribuyendo, a la interculturalidad estratégica, la afirmación y la reivindicación.

Son pocas las personas no afro que piensan con la memoria colectiva afroecuatoriana, decía Juan García Salazar. Pocas las que logran escuchar la voz de los abuelos y abuelas, pensar con sus saberes y comprender que no son producto o resultado de autoría individual. Para Juan García, Michael tú eres una de estas personas. Como Juan decía:

La tradición oral desde casa adentro es un abordaje complejo, más que todo porque es respetuoso, porque requiere ser respetada. El problema muchas veces es cuando está usado 'casa afuera' como citas que simplemente apoyan la idea de un autor individual, y que no apoyan o dan presencia al pensamiento de la colectividad que estas palabras, estas citaciones, construyen y reflejan ... En todo este proceso, el personaje del Abuelo Zenón es central; el rol de Zenón es como juntar el pensamiento en una sola voz. ...Cuando habla Zenón, es la gente que está hablando, están hablando también la memoria y la tradición. Zenón entonces tiene un rol útil e importante porque no pertenece a una sola persona, ... es la propiedad intelectual de la comunidad negra. Cuando Michael Handelsman está trabajando con Zenón, o cuando líderes de las comunidades trabajan con Zenón y dicen "escuchen Zenón está hablando", están llamando a la memoria y a la tradición, evocándolas; están dando el espacio para la memoria y la tradición para que hablen (Walsh y García 2015, 88-9).

Como pocas personas, tu manera de pensar con y citar a Zenón es respetuosa de su sentir colectivo y su poética cimarrona de afirmación y reivindicación. Difícilmente se puede entender eso dentro del marco académico occidental y de lo que ha sido reconocido por la academia como literatura afroecuatoriana. "Nosotros los que tenemos sembrado en nues- 
tro corazón el sentido de pertenencia a la comunidad, no solo hablamos de la comunidad, sufrimos con la comunidad, nuestro dolor es el dolor de la comunidad, somos la comunidad", dice Zenón (García 2010, 12). Es en este contexto de donde procede tu afirmación, Michael: "lejos de considerar a los artistas como sus principales representantes y defensores, las comunidades más bien se miran adentro al asumir la responsabilidad de su propia construcción como pueblo" (Handelsman 2008, 111).

Respetar esta construcción, escucharla e intentar pensar con ella, ha sido -y aún es- parte de tu apuesta como pensador-escritor, y también como hacedor de lo intercultural y decolonial. Sin pretensiones y necesidad de gloria o fama, has contribuido a la transformación del escenario y estatuto hegemónicos de "la literatura nacional". Pero también, y tal vez más importante aún, has mostrado cómo el trabajo académico-literario puede encarnar y encaminar un interculturalizar, decolonizar y plurinacionalizar.

Gracias, Michael, por todo eso, y por las semillas de un otro pensar-hacer-actuar que sigues sembrando. *

\section{Bibliografía}

García, Juan. 2010. Territorios, territorialidad y desterritorialización. Quito: Fundación Altropico.

Handelsman, Michael. 2001. Lo Afro y la plurinacionalidad: el caso ecuatoriano visto desde su literatura. Quito: Abya-Yala.

- 2005. Leyendo la globalización desde la mitad del mundo. Identidad y resistencias en el Ecuador. Quito: Editorial El Conejo.

—. 2008. "Nelson Estupiñán Bass en contexto". En Género, raza y nación en la literatura ecuatoriana: Hacia una lectura decolonial. Guaraguao. Revista de Cultura Latinoamericana, 4, 110-32. Barcelona: CECAL.

—. 2008. "Pretexto. Las literaturas 'pequeñas' en busca de sus lectores interculturales: el caso ecuatoriano". En Género, raza y nación en la literatura ecuatoriana: Hacia una lectura decolonial. Guaraguao. Revista de Cultura Latinoamericana, 4. Barcelona: CECAL.

León, Edizon, y Juan García. 2006. El color de la diáspora. Knoxville: University of Tennessee.

Walsh, Catherine, y Juan García. 2015. "Memoria colectiva, escritura y Estado. Prácticas pedagógicas de existencia afroecuatoriana”. En Cuadernos de literatura. Vol. XIX, n. ${ }^{\circ} 38$ (julio-diciembre): 79-98. 